\title{
RELATIONSHIP BETWEEN SYSTEMS AND ENVIRONMENT IN THE CONTEXT OF GLOBAL-WARMING
}

\author{
Krishna P. Sankhi, MSc. Vet. Sc. ${ }^{8}$
}

\begin{abstract}
Along with the change in the living standard of the people, science and technology based innovations have created many unwanted and detrimental consequences. Lacking the holistic and multi-perspective approach and ignoring the relationship between the systems and the environment have adversely affected our natural resources - soil, water and air to the extent of frequently occurring painful natural calamities and constantly increasing global warming. System Learning Approach, a systemic and holistic approach accommodates all these issues and these are reflected on the experiential learning process and hence there is little chance for wrong implementation. It is focussed on some livestock related environmental problems, particularly the methane gas emission from the ruminant animals and the ways to reduce it through green based feeding, increased productivity and their population control. It is also explored about the misuse of the land and the soil erosion and the way to improve the situation.
\end{abstract}

\section{Introduction}

The common understanding among the developmental workers is 'new ways of thinking' and selection of appropriate 'approach' for the development. The wrong choice may lead to negative response from the clients. System Learning Approach (SLA) has, recently been preferred and claimed as most appropriate to deal with complex and messy situations. It is a process-oriented approach wherein programs proceed as guided by learning experiences.

Many unwanted consequences occurred when the relationship between the components (subsystems) of the system and inter-related environment was ignored in the previous developmental processes. Some of the livestock related environmental issues are explored here with an objective of how the SLA in the developmental process can contribute to improve the environment of the universe - the global warming for example, even from a livestock development program development point of view.

\section{System Learning Approach}

The world is comprised of systems, each interacting with their environments and each possessing certain characteristics by which we can tell what system is and what is not (Bawden, 1986). Those characteristics include an on-going purpose or mission, components which interact and have certain degree of connectivity such that inputs are transformed into outputs, a boundary separating it from environment, resources and some guarantee of continuity. Another important characteristic of the systems is their "emergent properties of wholeness", that is, system as a whole is always different from the mere sum of its parts (Bawden, 1995). The properties of wholeness 'emerge' because of the (synergistic) nature of the relationships (i) between the parts, and (ii) between the system and its environment. Systemic development is a process-oriented learning approach to exploring development which is environmentally feasible, viable now and sustainable in the future.

\footnotetext{
${ }^{8}$ Senior Veterinary Officer, Directorate of Livestock Market Promotion, Hariharbhawan. Email : kpshankhi_062@yahoo.com
} 
The major concepts of SLA are experienced based learning and soft system methodology. Because of the following properties, this approach is becoming popular. Currently Community Livestock Development Project (CLDP) is using this approach due to its good experiences in Third Livestock Development Project (TLDP) period.

- Continuous learning process by which experience is transformed into knowledge for action,

- Learning how to help others learn,

- Based on praxis.

- Highly participatory in nature and utilizes the collective experience of the people,

- Facilitate improvement rather than implement a grand plan,

- Tend to improve human performance through debate and reflection,

- Collaborative approach - working with clients as a part of their system,

- Stimulate ideas and theories - formed, reformed and shared,

- Prefer multi-perspective and holistic approach rather than reductionist's single perspective approach,

- SLA places people at the center of change,

- Address the relationship between systems, sub-systems and environment,

- Concerns the environmental issues in the developmental process.

Systemic approach goes through multi-perspective observations of and reflection on concrete experiences (need, problems/issues). The reflective observations may include strength, weakness, opportunities, threats, useful and harmful consequences, environmental effects, experiences, contexts etc, and develop concepts before taking action on any project as cited in Kolb's learning cycle below. Hence there is little chance of wrong selection in the developmental processes.



Experiential Learning cycle with Learning style (Kolb, 1984)

It is necessary to estimate the 'system as a whole' we are trying to intervene it, we need to be aware of its sub-systems and their interrelationship. We also need to be aware that people 
are the most complex, uncertain and unpredictable part of any system, yet have the most effect on it or within it. Unless we involve the human element in a way satisfactory to all, we may not be able to affect the system - not at least in sustainable way. Let's consider an example of a farmer who is trying to cope with a complex practical situation. A technical specialist, say Veterinary officer or Livestock officer or Agronomist will be happy to advise the farmer on aspects related to his or her specialization. He or she will not take any responsibility for other aspects of the farmer's system. Dealing with only a part of the system may not change the system at all. Hence, the development facilitator must observe the overall contexts and consequences in addition to the elements stated above in the system as a whole we are trying to improve it.

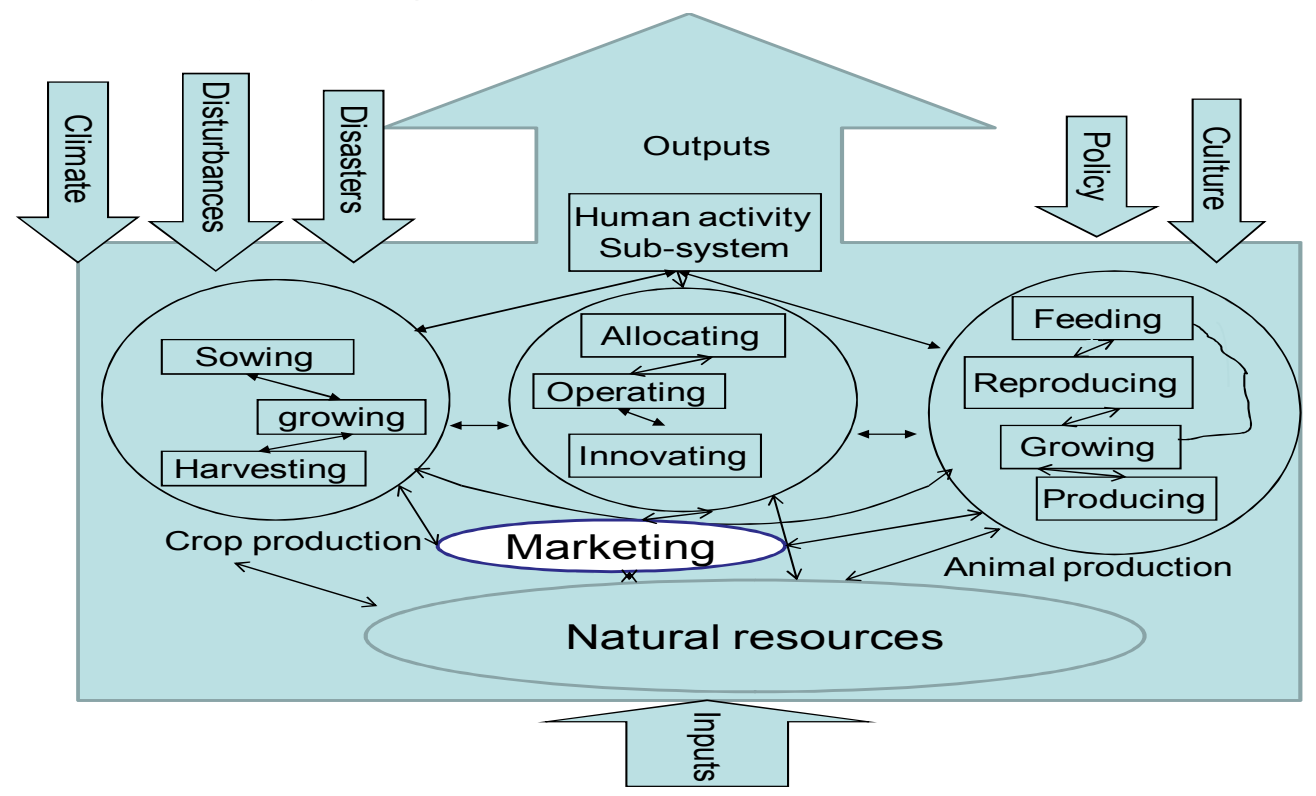

Fig - Farming system

Hence, farm design and management must incorporate the farming system of crops, livestock, pasture, forest and natural resources and an understanding of their eco-system.

\section{Effect of Natural Resources Mismanagement}

The natural resources mainly land, water and air are all needed to support life but these are under the threat of various stages of degradation due to man made activities. The fast growing industrialization and modernization have brought enormous change in the living standard of the people. However, it seems that the notion of the 'wholeness' was ignored in planning and implementation of these works; and some narrowly focussed science and technology based innovations have created many unintended and detrimental consequences even the 'emerge' of global warming due to increasing greenhouse effect. This terrible hazard has become one of the biggest and most interesting global issues now and the years to come. 


\section{The Greenhouse Effect}

When the greenhouse gases like carbon dioxide and methane are present in higher concentration in the atmosphere, they absorb more radioactive heat causing an increase in earth's temperature (LI, 1997) known as greenhouse effect. Methane emission in the atmosphere as a greenhouse is estimated to be 255 millions tonnes per year from all sources (WRI, 1990). It has also been estimated that the methane concentration in the atmosphere will be doubled by 2035 (Singh and Zimmerman, 1997). A major source of methane in the atmosphere is from non-biological materials, solid-waste, hard coal pipe, line leakage etc. Similarly, coal-based industries in China are producing 21.5 million tons of harmful gas Sulphur dioxide (Kantipur Television, 2006). A Norway scientist has reported that about 54000 sq. km. of north-pole is melting every year due to global warming. The fast disappearing polar ice will also contribute to the methane in the atmosphere as some methane is trapped in ice. The greenhouse emission is warning alarming situation of frequently occurring natural calamities like floods and draught, thus creating the problem of food scarcity, loss of life and shelter. Similarly, the change in climatic condition from the rise of global temperature would have an impact on activities like agriculture and animal husbandry. Temperature rise by $1^{\circ} \mathrm{C}$ in India reduces the rice yield by 7 percent and temperature rise by $0.5^{\circ} \mathrm{C}$ in winter reduces the wheat yield by 17 percent (Nepal Television, 2007). This would be of particular significance in a country like Nepal, which is mostly dependent on rain-fed agriculture.

\section{Livestock's Role for Greenhouse Effect}

Livestock farming is one of the important sources of greenhouse gas production. The emission of methane in the atmosphere from ruminant animals is reported to be 18 percent, which is equal to that of rice field (Singh and Zimmerman, 1997). Out of 55 millions of methane gas produced per year in India 10.4 million tonnes is contributed from ruminants alone (Ahuja, 1990). Rice field and ruminants are the major sources of methane in that country (Singh, 1995). ). It is also estimated that methane production per adult cattle and sheep per day is 250 liters and 40 liters respectively (Gnanaprakasham, 2000). Although these values are based on larger sized animals as compared to the breed existing in Nepal, the methane emission from the Nepalese ruminants, numbering about 7 millions cattle, 4 millions buffaloes and 8 millions goats and sheep would also be in significant volume. In ruminant, methane is a product of rumen digestion. This product not only contributes to add the greenhouse gases in the atmosphere but it also constitutes a loss of $4-15 \%$ of the animal feed energy (LI, 1997).

\section{Reducing the Livestock Contributed Greenhouse Effect through their Nutritional Management and Population Control}

Methane is produced in the rumen to act as hydrogen sink during the fermentation of carbohydrates. The two other natural resources of hydrogen sink in the rumen are unsaturated fatty-acids of feed and propionate formation during the process. Obviously, nutrition, especially the type and amount of carbohydrates, plays a very significant role in methane emission. There are the reports of reducing the ruminant methane production rate by $10-25 \%$ by simply changing the feeding pattern and manipulating rumen fermentation. In an experiment of a cow using Sulphur hexafluoride tracer technique, Karnal workers under the leadership of Dr. G.P. Singh found that supplementation of cold process urea-molassesmineral lick resulted in $11 \%$ reduction of methane emission; and that of $21 \%$ reduction on substitution of $50 \%$ concentrate mixture in adult rumen fistulated male animal diet (NDRI,1997). They have also reported the $8-23 \%$ reduction of methane emission by different combinations of green and dry fodder; legumes and non-legumes and other locally available 
green fodder. Hence, if we attempt to change the fermentation pattern towards propionate, it would meet twin objectives of increased productivity and environmental protection.

It is reported elsewhere that total methane production increases with increase of body weight and milk yield, and obviously high yielding cows have a higher total methane production. However, the rate of the production per $\mathrm{Kg}$ of milk is lower than that in low yielding animals. The Karnal researchers have cited that a 300 body weight cow producing $3 \mathrm{Kg}, 5 \mathrm{Kg}$ and $7 \mathrm{Kg}$ of milk have methane production of 163.8 litre, 163.8 litre and 174.8 litre per day; but the methane production value per $\mathrm{Kg}$ of milk will be $39.0,23.4$ and $17.8 \mathrm{~g} / \mathrm{Kg}$ milk respectively. Hence, if we increase the productivity of milk animals and reduce the massive population of unproductive or low yielding animals our contribution to environmental protection will be significant.

\section{Haphazard Land Use and Environmental Degradation}

There is increasing encroachment of forest, pasture and agricultural land by growing and migrating population in Nepal, particularly in Terai and urban areas. Our consistent tradition of crop cultivation, particularly maize and millets in the steep slopes and marginal lands of hills and mountain has accelerated the degradation process. Only an aspect of food grain production has been emphasized here, but the effects like permanent loss of fertile soil and risk of landslide is usually ignored. In spite of long experiences of such frequently occurring incidences, why don't we think for better alternatives instead of continuing the wrong practice? The available land can be properly used by best selection of agricultural commodities for cultivation. Fodder trees plantation and perennial grass cultivation to support the livestock farming could be the best selection in these locations. Similarly, horticulture farming and grass cultivation under fruit plants could be another model if the soil type and climatic condition are favourable. The income generated from these practices can buy more food grains than the land could produce. The awareness program for the respective farmers would help bring about the change.

Likewise, there is increasing trend of Local Bodies to invest their resources in link road construction even in sloppy villages of hills and mountain; and it is very common scenario of such works during dry months of the year and severe landslide in the following rainy season. There are numerous examples of land degradation because of the narrowly focussed planning and ignoring the systemic approach. When we think about the issue in multi-perspective approach, several questions arise in this context. Was it really essential to construct the road with so terrible risk? Isn't more economical and sustainable to use such land for agricultural farming, and transport the produces to nearest road by paying so cheaply available labour cost? What could be other alternatives for the developmental processes there? What are our past experiences and the contexts? Systemic approach includes all these reflective observations and develops concepts before decision making and its implementation.

\section{Green Energy Promotion}

Forest, shrub lands, pasture areas, green grass, crop residues and by-products are major animal feed resources. Over $50 \%$ of the total fodder supply comes from forest with forest trees supplying $20 \%$ (Parajuli, 2005). Forest alone contributes $30 \%$ of animal feed. Depletion of forest resources results in inadequate fodder supply to livestock. Unfortunately, the annual deforestation is estimated at $1.7 \%$ with $2.3 \%$ in hills and $1.3 \%$ in Terai (MFSC, 1999). Forest depletion results in reduction of soil nutrients and drying of water resources. It also reduces the soil binding properties making it vulnerable to disaster - landslide, mass wasting and erosion. In order to maintain the ecological balance forest area should cover at least $40 \%$ of the total land area; hence it is crucial for Nepal to stop the existing $39.6 \%$ of the forest land 
from any more degradation (NPC, 2002). Implementation of leasehold forestry with the partnership of local communities, packages for perennial leguminous grass cultivation in private, public and community land and forest, pasture development on barren land, adoption of well planned rotational grazing system (avoid overgrazing), promotion of stall feeding practice and extension of bio-gas production using manure increase the feed resources, reduce the forest depletion and improve the environment. But it requires again systemic approach and multi-sectoral efforts.

Greenery promotion is essential for animal heath promotion too. Green based ration for ruminants is economical and healthier as compared to concentrate based ration. Concentrate based carbohydrate will reduce the cellulolytic organisms in the rumen and increase the lactic acid producing bacteria with abnormal lactic acid production leading to 'acidosis'.

Most of the carbohydrates are fermented by the rumen micro-organisms to volatile fatty acids (VFA), namely acetic acid, propionic acid and butyric acid containing 2, 3 and 4 carbon atoms respectively. These VFAs are in ionized form in rumen and their proportion is remarkably stable with molar ratio usually being near 65:25:10 with roughage diet and 50:40:10 in concentrate diet. For normal feed containing both grass and concentrate feed the acetate, propionate and butyrate are in the ratio of 62,22 and 16 respectively. If the rumen $\mathrm{pH}$ falls bellow 5.5 due to inadequate grass or roughage in the feed 'lactic indigestion' develops and causes a variety of problems including ruminal acidosis, reduced acetic-propionic ratio, loss of appetite, decline in milk production and lower fat content in the milk. Therefore, the animal nutritionists typically recommend that incorporation of concentrate should be limited to $50-60 \%$ of the total amount of dry material, with the balance of ration as forage.

\section{Mismanaged Plastic Materials - An Environmental Issue}

The plastic materials scattered on land, along the road sides and everywhere are seriously impairing the plant development and animal health. Plastic bags are being used extensively as carry-pack from market as well as domestic waste disposal bag.

Ruminant animals are subjected to environmental hazards like injecting of hard-wares and polythene bags which may ultimately result into serious problems with functioning of animals. In urban areas, cattle are raised under semi-intensive system and have free access to scavenge on the heaps of waste and garbage littered on the street, road side and elsewhere. Because of the habit of allothrophagia, they tend to ingest these plastic bags, card-board pieces and papers along with kitchen waste and garbage. The ingested plastic materials remain undigested in the rumen and other parts of digestive tract causing blockage there resulting to various disorders - indigestion, recurrent bloat, impaction, peritonitis and death.

\section{Haphazard Drug Use - An Environmental Hazard}

Currently, huge amount of veterinary medicines and feed supplements, costing about Rs. 492 millions/year (Bhandari and Singh 2003) are used in Nepal. There is no legal guideline for judicial use of anti-microbial agents and any other drugs in this country. There are many reports of increasing emergence of bacteria resistant to anti-microbial agents due to indiscriminating uses of these drugs without laboratory diagnosis, haphazard doses, careless treatment course and improper route of administration. The defined withholding period of milk or meat from the animals treated with the drugs is usually ignored; and consumption of the drug residues containing products may become public health hazard. The drug resistance bacteria may also decrease the non-pathogenic microbial population, which ultimately paves way for deteriorating microbial environment and ecosystem. 


\section{Conclusion}

Many unwanted consequences are frequently occurring now because we did not consider much in developmental planning about the system as a whole and its relation with environment. The increasing ice-melting effect is one of them. Good management of the natural resources without disturbing much of their eco-systems is one of the important components of any developmental systems. Any undertaking, ignoring the relationship between the components of the systems, between the systems and the environment and between the systems themselves may bring the disasters.

It was never enough, in the name of sustainable development, to feed hungry people with feed, nor it is sufficient to teach them how to fish. The new challenge is to facilitate the people learning about the social ecology of sustainable fish - people relationship (Bawden, 1995).

\section{REFERENCES}

1. Ahuja, D., 1990: "Estimation of Regional Anthropogenic Emission of Green House Gases", U.S.E.P. A Report No. 20

2. Bawden, R., 1995: Systemic Development: A Learning Approach to Change. University of Western Sydney, Australia

3. Bawden, R., 1986: Essays in Sabbatical Reflection. University of Western Sydney, Australia

4. Bhandari, S. and Singh, S., 2003, "Annual Consumption of Veterinary Medicines and Feed Supplements in Nepal. Souvenir, VETCON'03. Nepal Veterinary Association.

5. Gnanaprakasham, V., 2000, "Roaming through rumen", Vet-link. Glaxo India Ltd.

6. Kantipur Television, Aug. 28, 2006: Nepali News, 20.00 P.M.

7. Kolb, D., 1984: Experiential Learning: Experience as the Source of Learning and Development, Prentice Hall, New Jersey.

8. LI, 1997: "Livstock International" Vol 1, Issue 3, July, Saharanpur, India.

9. MFSC, 1999: "Forest and Shrubs Cover of Nepal", Department of Forest Research and Survey. Ministry of Forest and Soil Conservation. Singh Durbar Kathmandu.

10. NDRI, 1997: "Measuring Methane Emission from Livestock: Towards Environment Friendly Livestock Farming". Livstock International Vol 1, Issue 3, July, Saharanpur, India

11. Nepal Television, May 25, 2007: Krishi Shamachar, 6.40 P.M.

12. NPC, 2002: Approach Paper of the Tenth Plan (2002 - 2007). National Planning Commission Singh Durbar.

13. Parajuli, D., 2005: "Integration of Livestock Production and Environmental Protection, Agriculture and Environment. Ministry of Agriculture and Cooperative, Singh Durbar, Kathmandu.

14. Singh, G.P., 1995: "Production of Greenhouse Gases and Indian Ruminant Livestock", Indian Dairyman, 47(9):23

15. Singh, G.P. and Zimmerman, P., 1997: " A New Method for Estimation of Methanefrom Ruminant using Sulphur hexafluoride tracer Technique". Pashudhan Vol 12, Issue 7, July, Bangalore, India.

16. WRI, 1990: World Resource Institute, Washington D.C. 